\title{
Study on food sampling routing system based on traveling salesman problem
}

\author{
Dao Chanh THUC ${ }^{1,2^{*}}$, Tzu-Chia CHEN $^{3^{*}}$ (D), Gunawan WIDJAJA ${ }^{4}$, Vera GRIBKOVA ${ }^{5}$, Andrey SHAKHOVSKOY ${ }^{5}$, \\ Paitoon CHETTHAMRONGCHAI ${ }^{6}$, Huynh Tan $\mathrm{HOI}^{7}$, Nguyen Thi THOI ${ }^{7}$, Hari Prapan SHARMA ${ }^{8}$
}

\begin{abstract}
The issue of preserving fresh food during the transportation is one of the long-standing issues for food distributors. On the other hand, the issue of vehicle routing is one of the most important issues in distribution management. Affecting the quality of food is the distribution process, which reduces the distribution time through vehicle routing plays an important role in reducing food spoilage. Therefore, in this study, the problem of vehicle routing in the distribution of perishable food materials is investigated. The time is different so that the distance is minimized and the capacities and time windows are not violated. This research aims to find facilities, identify the size of each cargo, and establish the most efficient vehicle routes to reduce overall costs at three levels in the event of a system failure. Undoubtedly, the traveling salesman issue is one of the most famous issues in the field of artificial intelligence.
\end{abstract}

Keywords: preserving fresh food; routing; overall costs; traveling salesman.

Practical Application: This research aims to optimize food sampling routing system to reduce overall costs.

\section{Introduction}

Today, competitive markets and the development of management concepts have forced companies to better design and manage supply chains. Supply chain management emphasizes the integration of chain members (Feizabadi et al., 2019; Gligor et al., 2019; Oghazi et al., 2018). Because to increase the efficiency of a supply chain, its decisions cannot be considered separately and optimized. Since the high role of the location factor, routing is not covered in the survival of a supply chain, so the integration of these elements will provide an efficient and effective supply chain (Elluru et al., 2019; Shavarani, 2019; Thürer et al., 2020). This study examines the design of a perishable food supply chain network with disruption risk, which includes facility location, flow allocation between facilities, and routing decisions. In this research, food distribution centres receive food from supply points and deliver it to demand centres. The purpose of this study is to provide a traveling salesman problem (TSP) model for locating distribution centres along with routing distribution vehicles from suppliers to demand points. The results of the research, along with its sensitivity analysis, indicate that the more we pay attention to costs and pay more, the less the deficit decreases, and the more the importance and attention to costs decreases, the greater the deficit. Also, the more attention is paid to the cost, the more coverage we will have and we can cover all areas with the highest cost.

Today's competitive world forces companies to make strategic and practical decisions to optimize and efficiently manage the processing of their logistics devices (Guzzo et al., 2019; Nagy et al., 2018; Tang \& Meng, 2021). The issue of vehicle location - routing is one of the important issues in logistics and is of particular importance due to the type of facilities and products. This is doubly important for highly perishable products. The location-routing problem consists of two warehouse location and vehicle routing problems, which in the mathematical model of location-routing, consider these two problems simultaneously and solve the problem (Rabbani et al., 2018; Wang et al., 2020; Zhang et al., 2019). Using customeroriented transportation systems, it is possible to expand existing active markets as well as create new markets, deliver perishable products to consumers in the shortest possible time, and increase customer satisfaction by minimizing delivery time, which leads to Conquering the relevant commodity market. Supply chains, especially global supply chains, face a wide range of risks that jeopardize the performance of suppliers and the entire supply chain. For example, natural disasters, strikes, and terrorist acts are among these risks. As a result, companies need to improve their

\footnotetext{
Received 19 July, 2021

Accepted 27 Aug., 2021

${ }^{1}$ An Giang University, Long Xuyên, Vietnam

${ }^{2}$ Vietnam National University, Ho Chi Minh City, Vietnam

${ }^{3}$ Dhurakij Pundit University, Bangkok, Thailand

${ }^{4}$ Universitas Krisnadwipayana, Jawa Barat, Indonesia

${ }^{5}$ K.G. Razumovsky Moscow State University of technologies and management (The First Cossack University), Moscow, Russian Federation

${ }^{6}$ Faculty of Business Administration, Kasetsart University, Bangkok, Thailand

${ }^{7}$ Language department, FPT University, Hanoi, Vietnam

${ }^{8}$ GLA University, Mathura, India

*Corresponding author: tzuchiachen1688@gmail.com; daochanhthuc@gmail.com
} 
management strategies to respond quickly to unforeseen events in the supply chain or reduce the adverse effects of unforeseen events. In most location models or supply chain network design models, it is assumed that production or distribution facilities are always safe and available. But when facilities are disrupted, the model structure changes completely, and current models do not work in these conditions. Therefore, these models should be designed to be effective in the presence of disruption risks. The risk of disruption occurs when the structure of the supply chain system undergoes a fundamental change due to lack of distribution facilities, storage, production, or the occurrence of malnutrition (Manners-Bell, 2014; Ross, 2015). Disruption of a supplier or a subsystem causes a shortage of supply or, at worst, disrupts the entire chain. There may be adverse consequences for the success of all existing companies in the supply chain in such a supplier environment. Lost costs, reduced market share, and penalties for closed contracts are all possible consequences of supply chain disruption (Ivanov et al., 2015).

In today's competitive environment, lean and agile are two strategically important elements for many manufacturers in the supply chain in a timely manner. Meanwhile, the effective role of goods distribution centers to the customer and reducing inventory maintenance costs has attracted the attention of many supply chain managers. Since transit warehousing is a key component of designing a lean supply chain, high-volume logistics companies have begun to use transit warehousing (Stavrulaki \& Davis, 2010). A study defines a transit warehouse as "receiving goods from a supplier or manufacturer and combining these goods with the goods of other suppliers or manufacturers for shipment to various final destinations." The U.S. freight industry also defines transit warehousing as "the process of moving goods from door to door and into goods without placing them in storage." Warehouse transit is a logistics strategy that aims to reduce inventory and increase customer satisfaction (Lovell et al., 2005). Goods are delivered to the customer from the supplier through the transit warehouse, and the items must be collected in the transit warehouse before sending to the customer and after weighing, packing, and sorting according to destination, in the shortest possible time by outgoing vehicles for Customers to be sent. The transit warehouse acts more as an inventory coordinator than as a store. Goods are usually stored in the transit warehouse for less than 42 hours, and the transit warehouse must be emptied at the end of the working day. Advantages of using transit warehouses instead of traditional warehouses include reduction of costs (warehouse costs, inventory maintenance costs, relocation costs, manpower costs reduction of procurement time and delivery) from supplier to customer, upgrading customer service, reducing storage space reduce inventory turnover, reduce excess inventory maintenance, reduce risk of loss, and the benefits of using transit warehouse instead of point-to-point delivery include reduced costs (transportation costs, manpower costs), mergers Shipments, upgrading resource utilization (for example, using the maximum capacity of a vehicle), is a better match between the goods shipped and the amount of demand (Cinar \& Onbaşi, 2021; Rodrigues et al., 2018).
In this research, the problem of two-level location-routing of goods transfer from the factory to customers through intermediate warehouses (distribution centre) is done. In the first level, decisions related to selecting active facilities from the factories and the potential distribution centre, and in the second level, decisions related to determining the number of products delivered to customers from the distribution centre and subsequently to the distribution centre from the distribution center the factories as well. We are dealing with vehicle routing. The designed supply chain network must be able to respond to customer needs when disruption risk occurs, such as facility disruption. Therefore, these networks must be designed to be able to provide products and services to customers at any time when disruption occurs. The purpose of this study is to locate the facilities and determine the size of each shipment and the most effective vehicle routes to minimize the total cost at three levels (factories, distribution centres, and customers) under the risk of system failure.

\section{Material and methods}

Researchers and various algorithms have always examined the topic of the traveling salesman to analyze their performance in the actual world, with numerous applications such as vehicle routing concerns, production design, customer service time, and so on (Applegate et al., 2011; Giaglis et al., 2004; Govindan et al., 2019; Seyyedi \& Ayati, 2021). Solving difficult problems, this issue has already been discussed in the literature. The purpose is to determine the shortest path between a sequence of cities (nodes) so that each city only meets once and then returns to the starting city. The main challenge in this regard is the number of cities; in fact, by increasing the number of nodes and thus creating sub-tours, accurate optimization methods are unable to solve this problem in a reasonable time, necessitating the development of novel algorithms and solutions to achieve optimal or acceptable solutions in a reasonable time (Molajou et al., 2021).

Considering the full weighted graph $G$, the itinerant salesman problem involves finding the Hamiltonian graph at the lowest cost. In fact, in this problem, each permutation of the graph nodes is an answer to a problem and a Hamiltonian cycle (Eppstein, 2007).

\subsection{Proposed algorithm to solve the TSP problem}

In this section, using a combination of two algorithms, forest optimization and colonial competition, a new method is presented, and the TSP problem is solved (Odili \& Kahar, 2016; Peker et al., 2013; Zhong et al., 2017, 2018).

\section{Create an initial population}

The hypothetical line with six nodes in the forest optimization algorithm of each tree as an answer to the problem consists of an array $1 \times(n+1)$ where $\mathrm{n}$ is the number of nodes of the problem, and the last cell of the array is related to the age variable of each tree. The figure shown in Figure 1 is 0 . In the proposed algorithm, the initial population is generated in random permutations 


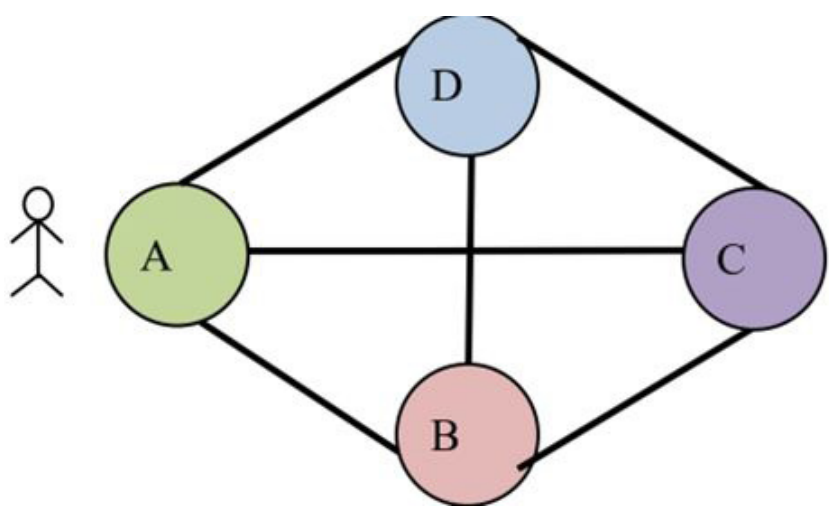

Figure 1. The shortest route by moving from one point and returning to the same.

from the numbers 1 to $n$. The forest optimization algorithm has two main operators: local data dissemination and global data dissemination. The local data distribution operator, which is a kind of local search, is applied to trees with zero lifespans and creates a neighborhood for these trees, and the age of all forest trees increases by one unit. The next section describes the local seed-dispersing operator.

\section{Local seed-dispersing operator}

To simulate a local seed-dispersing operator, we first consider the two elements of the selected tree, then replace the two nodes in those cells with each other. Repeat the above operation for the number of LSC parameters. In the continuation of the forest optimization algorithm, two parameters are used to limit the trees in the forest. The first variable is a lifetime that determines each tree's maximum age, and the other variable is the area limit, which is equal to the maximum number of trees in the forest. To be. First, we remove the trees that have reached lifetime from the forest and add them to the Candida collection. Candida collection includes trees that have been removed from the forest. Then, if the number of trees left in the forest is greater than the area limit variable, arrange the trees in the forest based on the value of their fitting function and select the area limit number of the best trees to survive in the forest, and add the rest to the candidate collection. We do. In this case, we enter the global seed dispersal stage with trees with better fitting functions.

\section{Global seed-dispersing operator}

In the proposed algorithm, the adsorption mechanism in the colonial competition algorithm is used to simulate the global seed-dispersing operator. In the algorithm of colonial competition, the colonialists try to assimilate the colonies with themselves by using the policy of attraction. In the method used to implement this operator, we act in such a way that the best tree available is considered as a colonizer and attracts the selected trees from the candidate list as follows:

1)Choose two random numbers $r_{1}$ and $r_{2}$, from the numbers
2)Form an auxiliary array and store the layout of the best tree from $r_{1}$ to $r_{2}$.

3)Start from the beginning of the selected tree from the candidate list and reach each node; if that node was not in the auxiliary array, we put it in the first empty cell of the auxiliary array and continue this process to the last cell.

4) Save the auxiliary array as a new tree and add it to the forest.

After performing the above operation, we set the age variable of the tree to zero and add it to the forest. Like other metaheuristic algorithms, three-stop conditions can be considered for the forest optimization algorithm: first, the algorithm repeats to a certain number, second, no change in the value of the best tree fitting function is observed during several iterations, and third, the third condition achieves a certain level of accuracy.

\section{Results and discussion}

Product distribution companies try to reduce initial distribution costs based on the number of vehicles used, distance, and total travel time. The issue of preserving fresh food during the transportation is one of the long-standing issues for food distributors. On the other hand, the problem of vehicle routing is one of the most important issues in distribution management. Total travel time, the number of vehicles, late penalties, and finally transportation costs are minimized, and finally, customer satisfaction is maximized. The issue of vehicle routing with time windows plays an important role in reducing food corruption and increasing customer satisfaction.

The traveling salesman problem (TSP) is one of the most important problems in the theory of computational complexity of algorithms (Hoffman et al., 2013). These issues were first raised by two scientists, the Irishman Hamilton and the British Kirkman. The problem of the traveling salesman is known by various names among mathematics and statistics scientists. One group called the issue of the traveling salesman the issue of the postman. It is noteworthy that the problem of the postman and the problem of the traveling salesman are the same, and each can be converted to the other with a simple conversion.

This is defined as always aiming to find a route for a salesman, who starts moving from his city and passes through a number of pre-determined cities and returns to his city in such a way that the length of his route should be minimal, and he should pass through each city exactly once (Figure 1).

The traveling salesman problem is one of the NP-hard problems, so to solve this problem, the genetic algorithm method has been used, which is an innovative method based on natural evolution. Due to the inefficiency and inefficiency of the genetic algorithm during the optimization operation, an attempt has been made to modify it by matching the parameters with the conditions. Therefore, the method used is called an adaptive genetic algorithm.

Consider Figure 2, for example. We want to find the shortest route starting from the desired city and returning to it. 
And the distance matrix between the cities will be as follows: This distance is calculated by calculating the Euclidean distance between the two cities. As you can see, the matrix is the result of a symmetric matrix. The result is asymmetric TSP, meaning that the return paths are equal (Table 1).

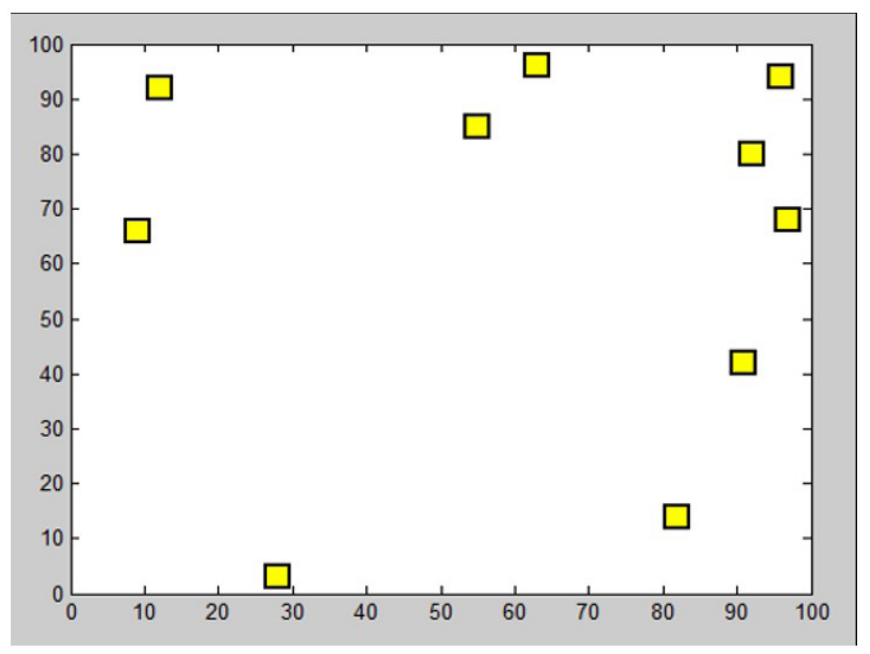

Figure 2. Different destinations used in the traveling salesman problem (TSP).

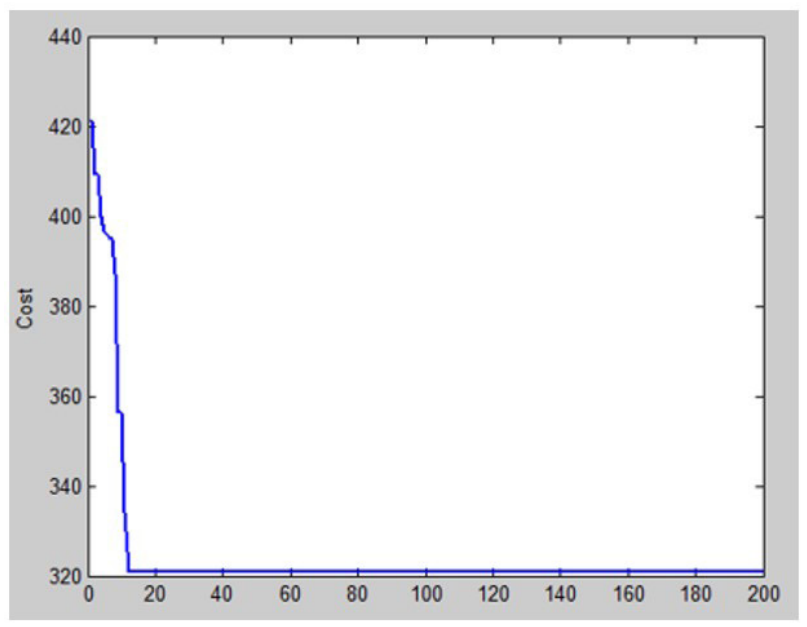

The number of answers to this problem is equal to the number of Hamiltonian cycles in a complete graph with $\mathrm{n}$ vertices, i.e., equal to (n-1)! Where $n$ is equal to the number of cities. (Note that in this graph, the nodes of the cities and the edges represent the route between the cities). And its temporal complexity is (O!) $\mathrm{n}$, which would be unsuitable even for a small number of cities.

For this reason, several methods have been developed to obtain the optimal answer to this problem:

A) Display the answer as a discrete string of permutations that can be used in the following algorithms: Genetic algorithms, refrigeration simulation, forbidden search, variable neighborhood search, ant colony optimization, harmony search, and other discrete optimization algorithms

B) Display the answer as to random keys that can be used in the following algorithms: Genetic algorithms, Particle Swarm Optimization, Colonial Competition Algorithm, Differential Evolution, Biogeographical Based Optimization, Evolutionary Strategies, Evolutionary Planning and other

C) Represent the answer in the form of pheromone-like matrices that can be used by all the algorithms mentioned in (b). Here we will first see the solutions to this problem based on the genetic algorithm and then the refrigeration simulation (see Figure 3):

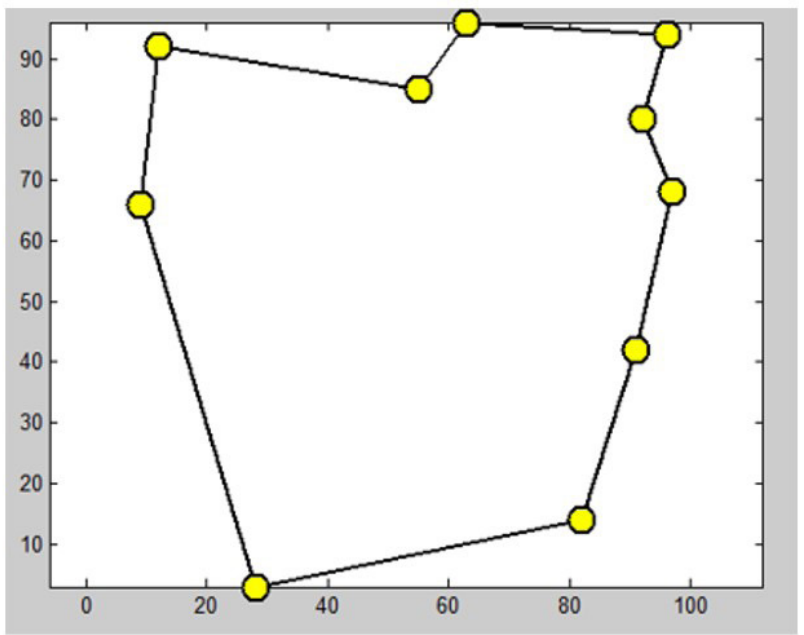

Figure 3. The result of implementing a genetic algorithm on ten elementary cities in a MATLAB environment.

Table 1. Symmetric TSP matrix.

\begin{tabular}{|c|c|c|c|c|c|c|c|c|c|}
\hline 0 & 29.4109 & 104.8046 & 66.7533 & 84.1724 & 89.627 & 55.109 & 75.9605 & 81.2158 & 56.0446 \\
\hline 29.4109 & 0 & 93.4933 & 38.0132 & 60.8276 & 85.44 & 74.0945 & 56.0803 & 52.2398 & 26.6833 \\
\hline 104.8046 & 93.4933 & 0 & 80.895 & 51.1566 & 26.1725 & 90.4268 & 43.566 & 84.0238 & 88.3233 \\
\hline 66.7533 & 38.0132 & 80.895 & 0 & 33.121 & 84.1724 & 100.1249 & 37.3363 & 14.5602 & 13 \\
\hline 84.1724 & 60.8276 & 51.1566 & 33.121 & 0 & 61.7738 & 99.368 & 13.6015 & 33.0606 & 44.0454 \\
\hline 89.627 & 85.44 & 26.1725 & 84.1724 & 61.7738 & 0 & 65.8027 & 49.7695 & 91.3947 & 88.0227 \\
\hline 55.109 & 74.0945 & 90.4268 & 100.1249 & 99.368 & 65.8027 & 0 & 86.3308 & 113.6002 & 94.7945 \\
\hline 75.9605 & 56.0803 & 43.566 & 37.3363 & 13.6015 & 49.7695 & 86.3308 & 0 & 41.9762 & 45.31 \\
\hline 81.2158 & 52.2398 & 84.0238 & 14.5602 & 33.0606 & 91.3947 & 113.6002 & 41.9762 & 0 & 26.0192 \\
\hline 56.0446 & 26.6833 & 88.3233 & 13 & 44.0454 & 88.0227 & 94.7945 & 45.31 & 26.0192 & 0 \\
\hline
\end{tabular}




\section{Conclusion}

Meta-heuristic algorithms have always performed well in the subject literature in solving TSP problems. Meanwhile, hybrid algorithms can effectively solve this problem by using the strengths of various innovative and meta-heuristic algorithms. The purpose of this study is to present a hybrid algorithm using the operators of two algorithms of forest optimization and colonial competition, which by combining the operators, has been able to show higher efficiency than the performance of the two algorithms separately. Since the basic forest optimization algorithm is an evolutionary algorithm for solving continuous optimization problems, in this paper, we first apply the changes and redefine its main operators and use the colonial competition algorithm absorption operator in the global data distribution operator of the new forest optimization algorithm. TSP is suggested. The computational results indicate that the proposed method has a good performance in solving this problem. In fact, the results show that this proposed hybrid algorithm can be effective as a basic algorithm for solving problems that are permutational.

The topic of traveling salesperson pickup and delivery with handling fees is discussed in this article. If a load that was not loaded last must be emptied, further handling actions are permitted to unload and reload other blocking access loads. Penalty costs are linked with the additional handling processes since they demand time and effort. The goal is to determine a viable path that minimizes overall expenses, including travel and penalty fees.

\section{References}

Applegate, D. L., Bixby, R. E., Chvátal, V., \& Cook, W. J. (2011). The traveling salesman problem: a computational study. Princeton: Princeton University Press.

Cinar, A., \& Onbaşi, E. (2021). Monitoring environmental microbiological safety in a frozen fruit and vegetable plant. Food Science and Technology, 41(1), 232-237. http://dx.doi.org/10.1590/fst.10420.

Elluru, S., Gupta, H., Kaur, H., \& Singh, S. P. (2019). Proactive and reactive models for disaster resilient supply chain. Annals of Operations Research, 283(1), 199-224. http://dx.doi.org/10.1007/ s10479-017-2681-2.

Eppstein, D. (2007). The traveling salesman problem for cubic graphs. Journal of Graph Algorithms and Applications, 11(1), 61-81. http:// dx.doi.org/10.7155/jgaa.00137.

Feizabadi, J., Maloni, M., \& Gligor, D. (2019). Benchmarking the triple-A supply chain: orchestrating agility, adaptability, and alignment. Benchmarking, 26(1), 271-295. http://dx.doi.org/10.1108/BIJ-032018-0059.

Giaglis, G. M., Minis, I., Tatarakis, A., \& Zeimpekis, V. (2004). Minimizing logistics risk through real-time vehicle routing and mobile technologies: research to date and future trends. International Journal of Physical Distribution \& Logistics Management, 34(9), 749-764. http://dx.doi. org/10.1108/09600030410567504.

Gligor, D., Gligor, N., Holcomb, M., \& Bozkurt, S. (2019). Distinguishing between the concepts of supply chain agility and resilience. International Journal of Logistics Management, 30(2), 467-487. http://dx.doi. org/10.1108/IJLM-10-2017-0259.

Govindan, K., Jafarian, A., \& Nourbakhsh, V. (2019). Designing a sustainable supply chain network integrated with vehicle routing: a comparison of hybrid swarm intelligence metaheuristics. Computers
\& Operations Research, 110, 220-235. http://dx.doi.org/10.1016/j. cor.2018.11.013.

Guzzo, D., Trevisan, A. H., Echeveste, M., \& Costa, J. M. H. (2019). Circular innovation framework: verifying conceptual to practical decisions in sustainability-oriented product-service system cases. Sustainability, 11(12), 3248. http://dx.doi.org/10.3390/su11123248.

Hoffman, K. L., Padberg, M., \& Rinaldi, G. (2013). Traveling salesman problem. In S.I Gass \& M.C. Fu (Eds.), Encyclopedia of operations research and management science (pp. 1573-1578). Boston: Springer. http://dx.doi.org/10.1007/978-1-4419-1153-7_1068.

Ivanov, D., Hartl, R., Dolgui, A., Pavlov, A., \& Sokolov, B. (2015). Integration of aggregate distribution and dynamic transportation planning in a supply chain with capacity disruptions and the ripple effect consideration. International Journal of Production Research, 53(23), 6963-6979. http://dx.doi.org/10.1080/00207543.2014.986303.

Lovell, A., Saw, R., \& Stimson, J. (2005). Product value-density: managing diversity through supply chain segmentation. International Journal of Logistics Management, 16(1), 142-158. http://dx.doi. org/10.1108/09574090510617394.

Manners-Bell, J. (2014). Supply chain risk: understanding emerging threats to global supply chains. London: Kogan Page.

Molajou, A., Nourani, V., Afshar, A., Khosravi, M., \& Brysiewicz, A. (2021). Optimal design and feature selection by genetic algorithm for emotional artificial neural network (EANN) in rainfall-runoff modeling. Water Resources Management, 35(8), 2369-2384. http:// dx.doi.org/10.1007/s11269-021-02818-2.

Nagy, J., Oláh, J., Erdei, E., Máté, D., \& Popp, J. (2018). The role and impact of Industry 4.0 and the internet of things on the business strategy of the value chain: the case of Hungary. Sustainability, 10(10), 3491. http://dx.doi.org/10.3390/su10103491.

Odili, J. B., \& Kahar, M. N. M. (2016). Solving the traveling salesman's problem using the african buffalo optimization. Computational Intelligence and Neuroscience, 2016, 1510256. http://dx.doi. org/10.1155/2016/1510256. PMid:26880872.

Oghazi, P., Rad, F. F., Karlsson, S., \& Haftor, D. (2018). RFID and ERP systems in supply chain management. European Journal of Management and Business Economics, 27(2), 171-182. http://dx.doi. org/10.1108/EJMBE-02-2018-0031.

Peker, M., Şen, B., \& Kumru, P. Y. (2013). An efficient solving of the traveling salesman problem: the ant colony system having parameters optimized by the Taguchi method. Turkish Journal of Electrical Engineering and Computer Sciences, 21, 2015-2036. http://dx.doi. org/10.3906/elk-1109-44.

Rabbani, M., Heidari, R., Farrokhi-Asl, H., \& Rahimi, N. (2018). Using metaheuristic algorithms to solve a multi-objective industrial hazardous waste location-routing problem considering incompatible waste types. Journal of Cleaner Production, 170, 227-241. http:// dx.doi.org/10.1016/j.jclepro.2017.09.029.

Rodrigues, A. O., Gandra, E. A., Conceição, R. C. S., Silveira, D. R., \& Timm, C. D. (2018). Good hygienic practices and identification of contamination sources in hotel food and beverage sector. Food Science and Technology, 38(Suppl. 1), 154-159. http://dx.doi. $\operatorname{org} / 10.1590 /$ fst.17417.

Ross, D. F. (2015). Distribution planning and control: managing in the era of supply chain management. Boston: Springer http://dx.doi. org/10.1007/978-1-4899-7578-2.

Seyyedi, M., \& Ayati, B. (2021). Treatment of petroleum wastewater using a sequential hybrid system of electro-Fenton and NZVI slurry reactors, future prospects for an emerging wastewater treatment 
technology. International Journal of Environment and Waste Management, 28(3), 328-348.

Shavarani, S. M. (2019). Multi-level facility location-allocation problem for post-disaster humanitarian relief distribution. Journal of Humanitarian Logistics and Supply Chain Management, 9(1), 70-81. http://dx.doi.org/10.1108/JHLSCM-05-2018-0036.

Stavrulaki, E., \& Davis, M. (2010). Aligning products with supply chain processes and strategy. International Journal of Logistics Management, 21(1), 127-151. http://dx.doi.org/10.1108/09574091011042214.

Tang, L., \& Meng, Y. (2021). Data analytics and optimization for smart industry. Frontiers of Engineering Management, 8(2), 157-171. http:// dx.doi.org/10.1007/s42524-020-0126-0.

Thürer, M., Tomašević, I., Stevenson, M., Blome, C., Melnyk, S., Chan, H. K., \& Huang, G. Q. (2020). A systematic review of China's belt and road initiative: Implications for global supply chain management. International Journal of Production Research, 58(8), 2436-2453. http://dx.doi.org/10.1080/00207543.2019.1605225.
Wang, Y., Peng, S., Zhou, X., Mahmoudi, M., \& Zhen, L. (2020). Green logistics location-routing problem with eco-packages. Transportation Research Part E, Logistics and Transportation Review, 143, 102118. http://dx.doi.org/10.1016/j.tre.2020.102118.

Zhang, S., Chen, M., \& Zhang, W. (2019). A novel location-routing problem in electric vehicle transportation with stochastic demands. Journal of Cleaner Production, 221, 567-581. http://dx.doi.org/10.1016/j. jclepro.2019.02.167.

Zhong, Y., Lin, J., Wang, L., \& Zhang, H. (2017). Hybrid discrete artificial bee colony algorithm with threshold acceptance criterion for traveling salesman problem. Information Sciences, 421, 70-84. http://dx.doi.org/10.1016/j.ins.2017.08.067.

Zhong, Y., Lin, J., Wang, L., \& Zhang, H. (2018). Discrete comprehensive learning particle swarm optimization algorithm with metropolis acceptance criterion for traveling salesman problem. Swarm and Evolutionary Computation, 42, 77-88. http://dx.doi.org/10.1016/j. swevo.2018.02.017. 